\title{
A Study of Chemical Deliveries as a Function of Cigarette Butt Length*
}

by

\author{
J.C. Young \\ Department of Statistics, University of Waterloo, Waterloo, Ontario, Canadit
}

and

J.C. Robinson and W.S. Rickert

Labstat Incorporated, Kithener, Ontario, Canada

\section{INTRODUCTION}

A number of publications have reported the delivery of various tobacco smoke constituents as a function of puff number and/or cigarette butt length (1-6). For deliveries reported on a per puff basis there is some theoretical justification for relating the logarithm of the delivery to the butt length and/or puff number at least for condensate (7), carbon monoxide (8) and low molecular weight constituents such as $\mathrm{N}_{2}, \mathrm{O}_{2}, \mathrm{H}_{2}, \mathrm{CH}_{4}$ and $\mathrm{CO}_{2}(9,10)$. For total deliveries an empirical yield formula has been advanced (11) to aid in data manipulation and interpretation.

International comparison of total deliveries is made difficult by the fact that butt length standards are not uniform from country to country $(12,13)$. Published studies have for the most part tended to report the deliveries of an isolated chemical constituent for one or more types of experimental cigarettes without specification of a functional relationship between diemical delivery and butt length (puff number). The form of the functional relationship between demical delivery and butt length therefore must be known if accurate estimation is to be made of delivery at a butt length other than the standard length. The present study was conducted in order to investigate the suitability of linear and log linear models to represent the relationship between chemical deliveries (condensate, nicotine, total hydrogen cyanide (HCN) and carbon monoxide (CO)) and butt length. Two statistically designed experiments were employed to explore these relationships for ten major commercial brands of cigarettes.

\footnotetext{
* Received: 10rh June 1980 - accepted: 11th March 1981.
}

\section{METHODS}

\section{Analytical Procedures}

Cigarettes were purchased from wholesalers during March and April 1978 in five major cities across Canada and conditioned at $60 \%$ relative humidity and $22^{\circ} \mathrm{C}$ for a minimum of 48 hours before testing. Cigarettes were then smoked on a smoking madine under standard conditions (14) with the exception of butt length. Nicotine and water were estimated by a gas chromatographic procedure, and dry condensate deliveries were obtained by subtracting nicotine and water from total particulate matter (TPM) $(13,15)$.

Determination of $\mathrm{HCN}$ required modification of the Phipps and Bird 20-port smoking machine (Machine I) to accommodate trapping solutions directly behind each port. Five cigarettes of a particular brand were smoked for analysis and the particulate matter was trapped on a Cambridge filter. The gas phase was led directly through a sintered glass frit fitted into a trap containing $35 \mathrm{ml}$ methanol thermostated to $2^{\circ} \mathrm{C}$ by a circulating bath containing 50\% ethylene glycol. Immediately upon completion of the smoking run, a $4 \mathrm{ml}$ sample from each of the twenty traps was taken and placed in a sample cup, which was sealed with Parafilm and inserted into an AutoAnalyser sample turntable. The reactions employed are well established: the determination of HCN is based on the König reaction in which cyanogen chloride (obtained from the reaction of Chloramine-T with $\mathrm{HCN}$ ) reacts with pyridine to produce glutaconic aldehyde which in turn forms a coloured compound with pyrazolone.

$\mathrm{HCN}$ yield is the sum of the gas phase deliveries 


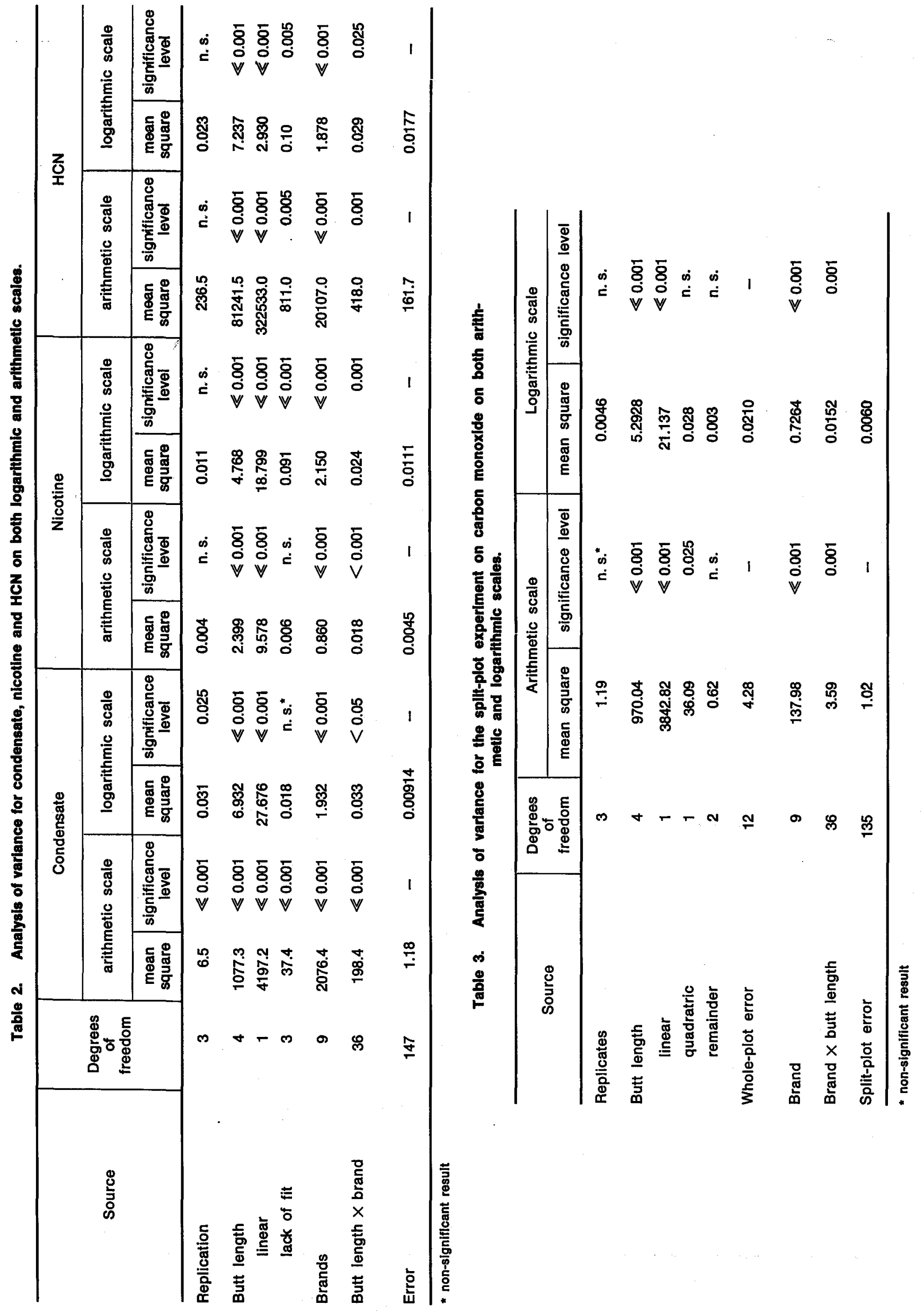


and the HCN contents of total particulate matter, estimated from aliquots of the solution prepared for nicotine and water determination $(14,15,16)$.

Further details, including the instrumentation and chemistries necessary for determination, have been published elsewhere (16). Estimates of $\mathrm{CO}$ concentration were provided by a non-dispersive infra-red analyser (ATCOM) coupled to a Filtrona Model 300 20-port smoking machine (Machine II).

\section{EXPERIMENTAL DESIGN}

The characteristics of the cigarettes chosen for the study have been summarized in Table 1 . These brands were unventilated filter tipped cigarettes chosen to represent three distinct condensate categories: high $(17-18 \mathrm{mg})$, medium (14-15 mg), and low-condensate $(8 \mathrm{mg})$ levels. To measure consistency within each condensate category, four high-condensate, four medium-condensate and two low-condensate brands were chosen. Specific brands were picked to represent a significant proportion of Canadian sales (56\% in total). Brands also had to have on overwrap length such that they could be smoked to a $23 \mathrm{~mm}$ butt length.

The ten brands labelled from $\mathrm{A}$ to $\mathrm{J}$ were smoked to lengths of 23,30,37, 44 and $51 \mathrm{~mm}$ corresponding to an observed maximum burning rate of approximately $7 \mathrm{~mm}$ per puff; the lowest and second lowest butt length represent the American and Canadian standard respectively $(12,13,14)$.

Butt length rather than puff number was chosen for the independent variable not only because international standards call for smoking the cigarette to a fixed butt length, but because puff number itself is dependent on cigarette construction and taking the same number of puffs on two cigarettes is unlikely to lead to the same butt length.

With ten brands and five butt lengths, one full replicate of the experiment consists of fifty observations. It was decided to run four full independent replicates.

Table 1. Brand characteristics.

\begin{tabular}{l|c|c} 
Table 1. Brand characteristics. & $\begin{array}{c}\text { Nominal } \\
\text { con- } \\
\text { densate } \\
\text { (mg) }\end{array}$ & $\begin{array}{c}\text { Nicotine } \\
\text { (mg) }\end{array}$ \\
\hline
\end{tabular}

High-condensate level (17-18 mg)

$\begin{array}{lrr}\text { A: king size filter tip } & 18 & 1.2 \\ \text { B: king size filter tip } & 17 & 1.1 \\ \text { C: regular size filter tip } & 18 & 1.2 \\ \text { D: regular size filter tip } & 18 & 1.2\end{array}$

Medium-condensate level (14-15 mg)

E: king size filter tip

F: regular size filter tlp, "light"

G: regular size filter tip

H: regular size filter tip, "light"

Low-condensate level $(8 \mathrm{mg})$

I: regular size filter tip

J: regular size filter tip
The necessity of using two smoking machines complicated the experimental design since each machine: required a separate procedure for butt length adjustments.

\section{Design for Machine I (Phipps and Bird)}

Estimates for condensate, nicotine and HCN were obtained with the Phipps and Bird 20-port srooking machine. The butt length can be controlled independently for each port within a run of this machine. Thus there were no physical restrictions on the experimental design for these three parameters. The four full replicates were completed in ten runs with one full replicate being run on each of ports $1-5,6-10,11-15$ and $16-20$. The 50 brand $x$ butt length combinations were assigned to ports completely at random within each replicate.

\section{Design for Machine II (Filtrona 300)}

CO deliveries were estimated using a Filtrona 300 twenty-port machine. Since in this case butt length adjustment of individual ports was not possible, it was necessary to smoke to only two randomly chosen butt lengths per run (one for ports $1-10$ and another for ports 11-20). The first complete replicate consisted of randomly permuting the five butt lengths over runs $1-5$ on ports $1-10$; the ten brands were then assigned to ports completely at random within each run of a given butt length. The other three replicates were completed by following the same procedure on runs 1-5 for ports 11-20 and on runs $6-10$ for ports $1-10$ and 11-20. A new randomization was used each time for the assignment of butt lengths to runs and brands to ports within runs. The restriction on completely random assignment of brand $\times$ butt length combinations to ports within replicates must be taken into account in the analysis: details on the appropriate "split-plot" or "nested" analysis can be found on pages. 369-373 of (17).

\section{RESULTS AND STATISTICAL ANALYSIS}

The analyses of variance for the experimental results are given in Table 2 for condensate, nicotine and $\mathrm{HCN}$ and in Table 3 for $\mathrm{CO}$. Both tables contain analyses of the results as measured (arithmetic scale) and after transformation to a logarithmic scale. Note that, because of the split-plot design, the $\mathrm{CO}$ analysis has two error terms: the whole-plot error which is the mean square that must be used in testing for replicate and butt length effects and the split-plot error to be used in testing brand effects and the interaction of brands with butt lengths. Both wet and dry condensate results were analysed in a similar manner, the characteristics were essentially the same in both instances. Wet condensate results are presented here. 
Figure 1. Condensate delivery (logarithmic scale) ve. butt length.

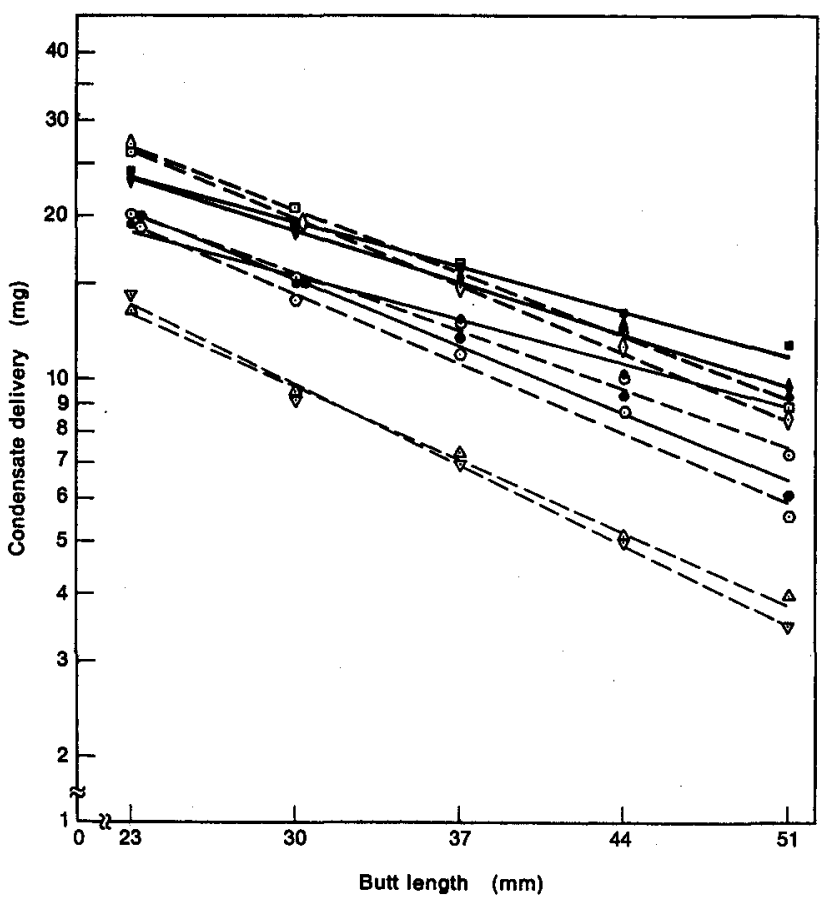

Figure 3. Nicotine delivery (arithmetic scale) vs. butt length.

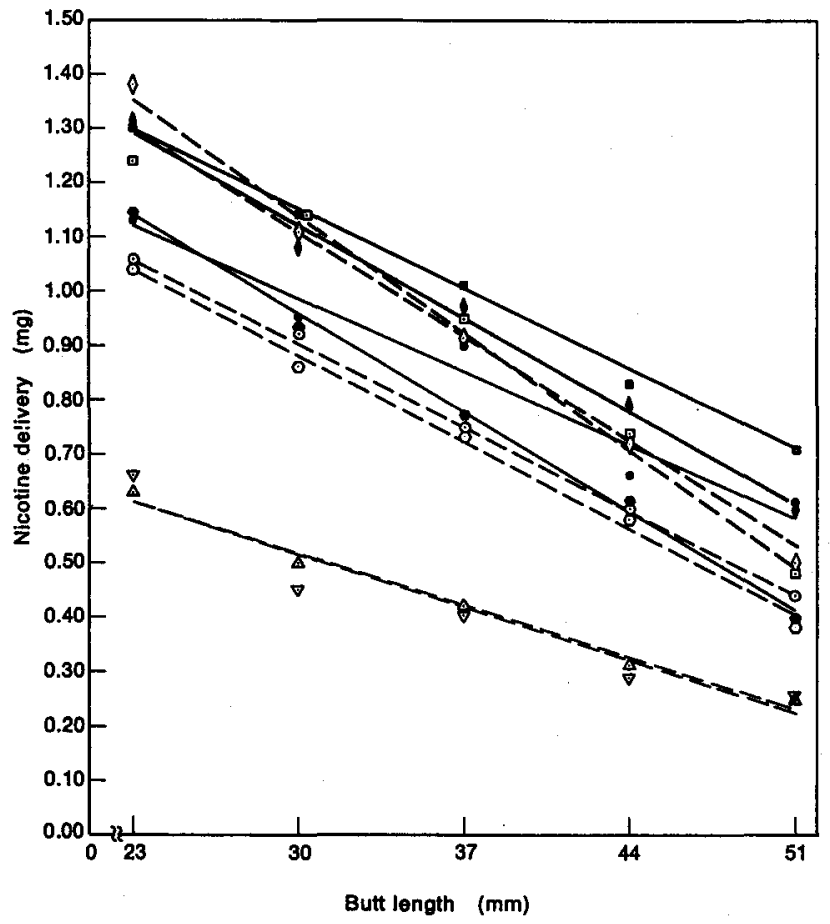

Flgure 2. Carbon monoxide delivery (logarithmic scale) ve. butt length.

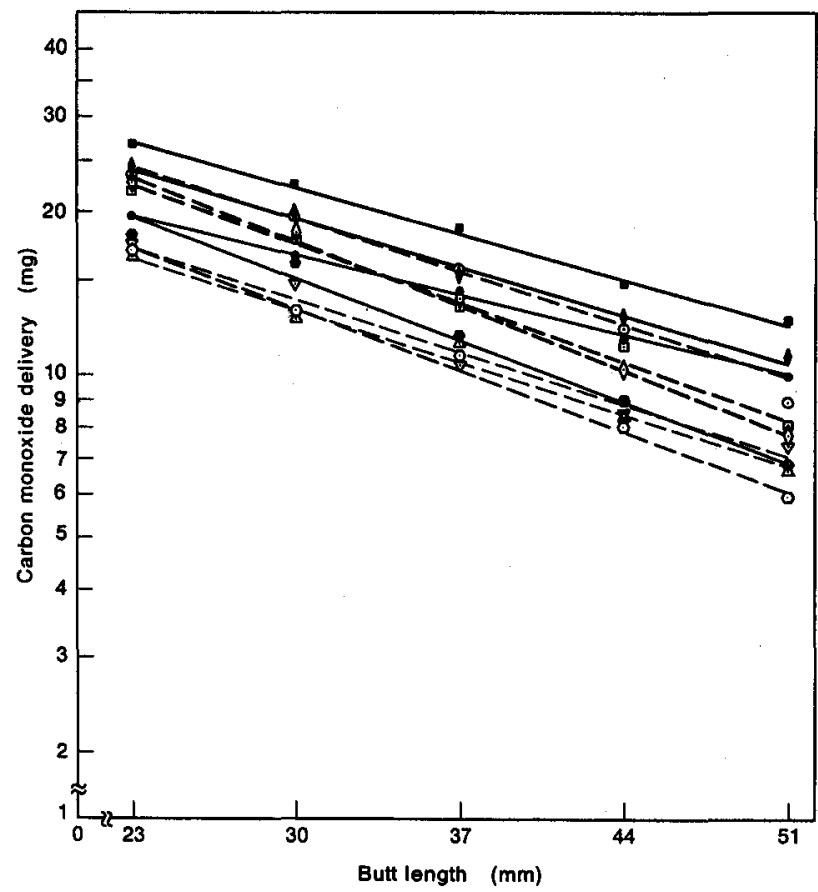

Figure 4. Hydrogen cyanide dellvery (arithmetic scale) ve. butt length.

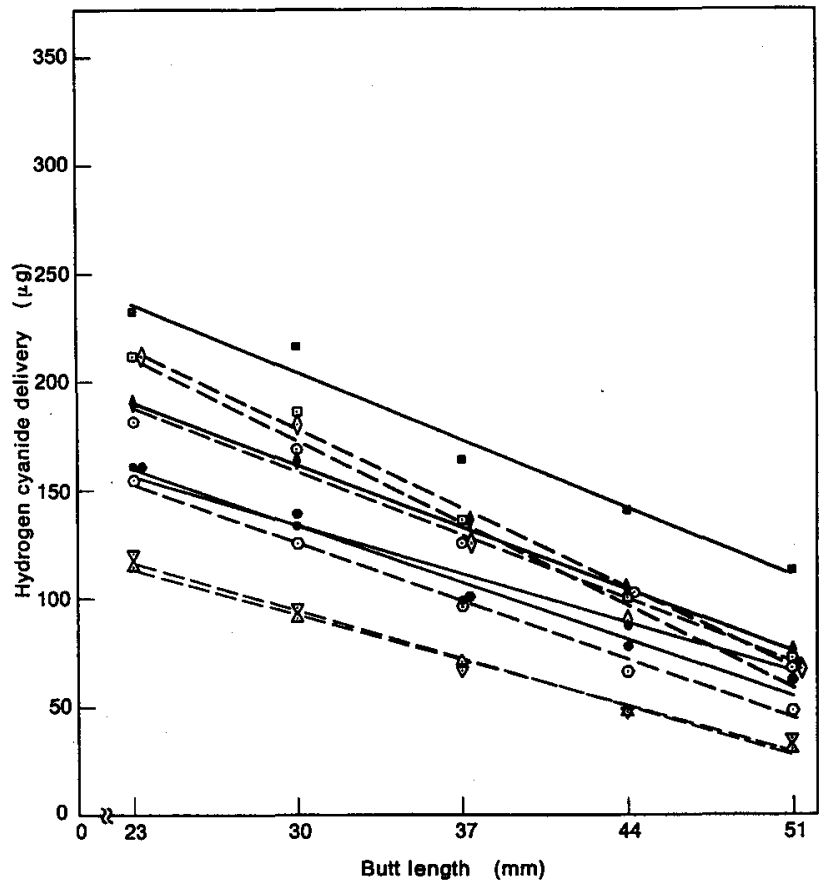

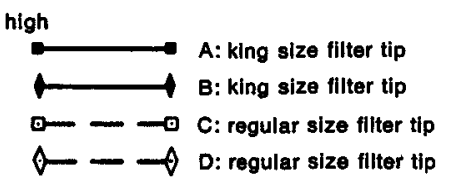

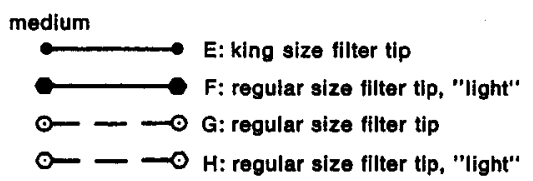

low

$\nabla-\longrightarrow$ I: regular size filter tip

$\triangle-\triangle$ J: regular size filter tip

O- - G: regular size filter tip

- $-\mathrm{H}$ : regular size filter tip, "light" 
Since brands were chosen on the basis of distinctly low, medium or high-condensate levels (see Table 1), it is not surprising to see that the main effect of brands is highly significant on both scales for all four parameters. The consistently significant butt length effect is also to be expected. Of greater interest is the consistently significant interaction. Details of a thorough study of this interaction are presented in Table 7 and will be discussed later.

The degree of curvature in the relationship between each of the parameters and butt length was studied using orthogonal polynomials as described on pages $460-465$ of (17). The main effect of butt length (4 degrees of freedom) was split into linear component (1 degree of freedom) and a lack of fit component (3 degrees of freedom) for condensate, nicotine and HCN (Table 2) and into linear, quadratic and ladk of fit terms for $\mathrm{CO}$ (Table 3). The corresponding mean squares and significance levels for these two components of the main effect of butt length are reported below the corresponding mean square term for butt length in Tables 2 and 3.

Although there are strongly significant departures from linearity for the variation of both condensate and $\mathrm{CO}$ with butt length on an arithmetic scale, there is no evidence that there are significant departures from linearity on the logarithmic scale. The opposite is true for nicotine delivery which departs significantly from linearity on the logarithmic scale but does not on the arithmetic scale. Figures $1-3$ depict the variation of each of the parameters with butt length using the scale on which the parameters appear to vary in a linear fashion as determined above.

HCN seems to depart significantly from linearity on both scales. Examination of quadratic and higher order orthogonal polynomials for $\mathrm{HCN}$ did not suggest any consistently smooth curve shape on either scale, thus HCN is plotted on an arithmetic scale in Figure 4. It can be seen that the fluctuation of the $\mathrm{HCN}$ values about the regression line is much more erratic than for the other three parameters (Figures 1-3); there cerrainly is no hint of a consistent, smooth curve.

Because of the significant brand and butt length interactions (see Tables 2 and 3), a study of the linearity on each scale was done for each brand individually. The results of this analysis are summarized in Table 4 . These results provide further evidence that condensate and $\mathrm{CO}$ are consistently linear on a logarithmic scale with nicotine being consistently linear on an arithmetic scale. It

Table 4. Number of brands dlsplaying signiflcant lack of fit.

\begin{tabular}{c|c|c}
\hline $\begin{array}{c}\text { Arithmetic } \\
\text { scale }\end{array}$ & $\begin{array}{c}\text { Logarithmic } \\
\text { scale }\end{array}$ \\
\hline
\end{tabular}

\section{Condensate}

5

0

Nicotine

0

3

Carbon monoxide

Hydrogen cyanide is however interesting to note that relatively few individual brands show lack of fit on the alternative scale especially for condensate and nicotine. One possible explanation is that tests for individual brands are less sensitive than the overall test reported earlier. This may be the reason why we found no evidence of a significant departure of the HCN results from linearity on either scale for the individual brands (see Table 4).

Further evidence that condensate does not vary with butt length in the same manner as nicotine is provided in Tables 5 and 6. Table 5 gives the result of an analysis of variance of the ratio of nicotine to condensate for the ten brands. The significant difference in this ratio from brand to brand is not surprising. Of greater interest is the significant difference in this ratio for different butt lengths and, as evidenced by the lack of significant interaction, the fact that the pattern of variation in the nicotine : tar ratio with butt length is consistent across all ten brands. Table 6 gives the average, over all brands and replicates, of the nicotine : tar ratio for each of the five butt lengths. It can be seen that while the ratio is consistent for the longest three butt lengths it starts to fall off at $30 \mathrm{~mm}$ and has dropped considerably at the $23 \mathrm{~mm}$ butt length. This observation is consistent with the conclusion that while nicotine continues to increase in a linear manner as the cigarette is smoked to a shorter butt length, the condensate level (the denominator of the ratio) starts to increase more rapidly as shorter butt lengths are reached.

Table 7 presents a thorough breakdown of the sums of squares corresponding to the brand main effect and the brand by butt length interaction. These two sums of squares have been broken into components that test spe-

Table 5. The analysis of variance of the nicotine : condensate ratio.

\begin{tabular}{l|c|c|c}
\hline Source & $\begin{array}{c}\text { Degree } \\
\text { of } \\
\text { freedom }\end{array}$ & $\begin{array}{c}\text { Mean } \\
\text { square }\end{array}$ & $\begin{array}{c}\text { Significance } \\
\text { level }\end{array}$ \\
\hline Replication & 3 & 0.0146 & 0.05 \\
Butt lengths & 4 & 0.0909 & $<0.001$ \\
Brands & 9 & 0.0188 & $<0.001$ \\
Brand $\times$ length & 36 & 0.0048 & n. s.* \\
Error & 147 & 0.0052 & \\
Total & $\underline{199}$ & & \\
\hline
\end{tabular}

* non-slgnificant result

Table 6. The variation of the nicotine : condensate ratio (as averaged over all 10 brands) with butt length.

\begin{tabular}{|c|c|}
\hline Butt length (mm) & $\begin{array}{c}\text { Average } \\
\text { nicotine : condensate } \\
\text { ratio } \\
\text { (all } 10 \text { brands) }\end{array}$ \\
\hline 23 & 0.053 \\
\hline 30 & 0.058 \\
\hline 37 & 0.063 \\
\hline 44 & 0.063 \\
\hline 51. & 0.064 \\
\hline
\end{tabular}




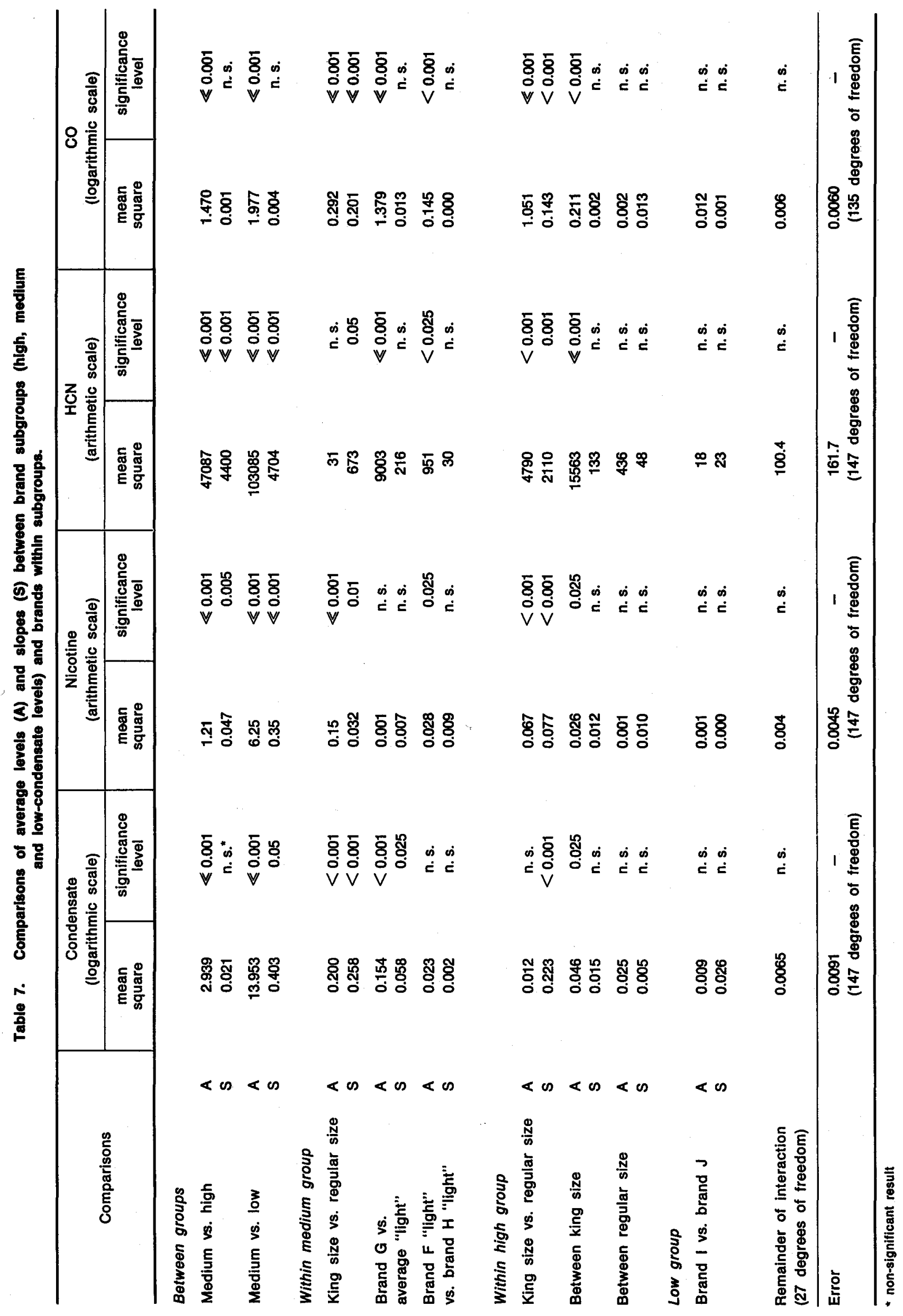


cific hypotheses regarding brand differences using orthogonal contrasts as illustrated on pages 346-349 of (17). Comparison of both average levels and of slopes in the relationship between the parameter and butt length are included in the table. In each instance comparisons are made between the overall average levels and slopes between the three condensate level groups, between subgroups within the groups and between brands within subgroups.

Again high significance levels of the differences between average levels are not surprising and have been included mainly to indicate that very specific hypotheses regarding the nature of average treatment differences can be tested using orthogonal contrasts. The breakdown of the 36 degree of freedom interaction terms into tests for differences in slopes is of more general interest. With the exception of $\mathrm{CO}$, there is generally quite strong evidence of significantly different average slopes between the major (condensate level) brand groups. However within brand groups the only consistently significant slope differences are between king size and regular cigarettes. Since the sums of squares for the remaining 27 degrees of freedom for interaction are not significant for any of the four parameters, the significant slope differences account for all of these interactions. The significant interactions have been represented in Figures 1 to 4 by non-parallel straight lines.

\section{DISCUSSION}

Papers by Byckling (6) and Curran and Kiefer (4) provide a theoretical basis in support of different functional relationships for condensate and nicotine delivery on butt length. Byckling suggests that the filtration power of the tobacco rod declines with increasing length for nicotine but is independent of length for condensate (6). Curran and Kiefer demonstrate that filtration is a dynamic process and that portions of total particulate matter (TPM) and nicotine are captured and subsequently eluted as the burning zone advances down the tobacco column (4). Since TPM is eluted to a lesser extent than nicotine, TPM accumulates and is released in the later puffs only at the point where the burning zone reaches the deposit. Nicotine on the other hand is eluted puff by puff and hence does not build up to the same extent as TPM. It is not surprising then to find a marked increase in TPM with the later puffs. Furthermore the data of Curran and Kiefer (4) seem to support our conclusion for condensate and nicotine in that a plot of TPM vs. puff number seems linear with TPM on a logarithmic scale, while nicotine vs. puff number seems linear with nicotine on an arithmetic scale. Plots of TPM and $\log$ nicotine display definite curvature. Similarly plots of Bydkling's data (6) demonstrate the linearity of an arithmetic relationship for nicotine and a logarithmic relationship for TPM vs. butt length particularly for the range of butt length similar to that in this study. Thus there is both theoretical and empirical support of a logarithmic model for TPM (and condensate) and an arithmetic model for nicotine.

Baker and Crellin (8), Muramatsu, Mikami, Naito and Tomita (9) and Owen and Reynolds (10) provide a sound theoretical basis for a logarithmic functional relationship between $\mathrm{CO}$ delivery per puff and butt length or puff number. Although dilution is shown to be an appreciable factor influencing $\mathrm{CO}$ loss in the case of cigarettes with perforated paper (9), diffusion loss is the major factor for cigarettes constructed from ordinary paper (8). Diffusion loss is practically independent of the porosity of the paper (9) but the loss decreases with each puff as the area of the paper decreases. These processes account for the increase of $\mathrm{CO}$ per puff with butt length or puff number.

It is, however, not clear how models based on delivery per puff can be modified to adequately describe the total delivery of $\mathrm{CO}$ accumulated at a specific butt length. Perhaps for this reason, empirical yield expressions have been advanced to describe total deliveries (11).

The conclusion with respect to $\mathrm{CO}$ is not easily confirmed from the literature. Although two papers $(2,18)$ investigate the dependence of $\mathrm{CO}$ on puff number, in one paper only is it done at a sufficient number of points to discriminate between the arithmetic and $\log$ arithmic models (19). A plot of $\log \mathrm{CO}$ delivery vs. puff number for Rideard and Owen's data demonstrates the suitability of the logarithmic relationship over the arithmetic particularly for larger puff numbers.

Data on HCN delivery published by Newsome, Norman and Keith (20) provide no convincing evidence that a logarithmic model is superior to an arithmetic one. Perhaps the fact that $\mathrm{HCN}$ is distributed over both the particulate and gas phase contributes to the complexity of its dependence on butt length. On the other hand, if the form of the functional dependence of HCN delivery on butt length is different for different brands, this could also explain the fact that neither linear nor $\log$ linear models provide an adequate model for the regression of average $\mathrm{HCN}$ delivery on butt length (Tables 2 and 3). In any event additional experimentation is necessary before an adequate model for $\mathrm{HCN}$ delivery can be confirmed.

\section{SUMMARY}

It should be emphasized that the major conclusion of this paper is not that any particular parameter is linear on any particular scale, but that there are highly significant differences in slope, intercept and perhaps even linearity between brand groups and even brands within groups. In fact, although several brands do seem to be adequately linear on either arithmetic or logarithmic scales they very clearly do behave differently from each other. There is also quite strong evidence that condensate and nicotine are not linear on the same scale, with condensate being approximately linear on the logarith- 
mic scale and nicotine approximately linear on the arithmetic scale. On the basis of the above it is quite clear that the ranking of brands on the basis of measured value of any parameter will depend strongly on the butt length at which the parameter was measured. It is therefore apparent that international comparison of deliveries requires redetermination of deliveries at the new butt length standard rather than mathematical manipulation using a single functional relationship.

The form of a suitable functional relationship for $\mathrm{HCN}$ cannot be ascertained from the present study and will require additional experimentation. The statistical design and analysis proved worthwhile in model discrimination for the other three parameters.

\section{ZUSAMMENFASSUNG}

Aus dieser Arbeit - dies ist hervorzuheben - ergibt sich als wichtigste Schlußfolgerung nidt, daß ein bestimmter Parameter sich in jedem gegebenen Maßstab linear verhält, sondern, daß es zwischen den Markengruppen und selbst zwischen den Marken innerhalb einer Gruppe in hohem Maße signifikante Unterschiede hinsichtlich Steigung, Achsenabschnitt und möglicherweise sogar hinsichtlidh der Linearität gibt. Wenn mehrere Marken auch in ihren Ergebnissen im arithmetischen wie im logarithmischen Maßstab hinreichend linear zu sein scheinen, so verhalten sie sich in Wirklichkeit doch sehr unterschiedlich. Es konnte auch mit recht großer Sicherheit beobachtet werden, $\mathrm{da} B$ sich Kondensat und Nikotin nicht im selben Maßstab linear verhalten, sondern daß die Ergebnisse für Kondensat im logarithmischen Maßstab und die für Nikotin im arithmetischen Maßstab annähernd linear waren. Aus diesen Befunden ergibt sich eindeutig, $\mathrm{da} B$ die Einstufung von Cigarettenmarken auf der Basis von Meßergebnissen für einen bestimmten Parameter in starkem Maße davon abhängig ist, bei welcher Stummellänge dieser gemessen wurde. Für einen Vergleich der Rauchausbeuten auf internationaler Ebene ist daher offensichtlich nicht so sehr die mathematische Berechnung unter Benutzung einer einzelnen funktionalen Beziehung erforderlich, sondern vielmehr die erneute Bestimmung der Meßwerte mit dem neuen Standardmaß für die Stummellänge.

Ober eine geeignete funktionale Abhängigkeit von $\mathrm{HCN}$ geben die vorliegenden Untersuchungen keinen Aufschluß; in dieser Hinsicht sind weitere. Versuche erforderlich. Zur Unterscheidung der Modellvorstellung für die anderen drei Parameter erwies sich die statistische und experimentelle Planung dieses Forschungsvorhabens jedoch als geeignet.

\section{RESUME}

Il convient de souligner que la conclusion essentielle de cet exposé n'est pas le fait qu'il existe un paramètre linéaire particulier dans une échelle particulière quel- conque, mais qu'il y a des différences significatives en ce qui concerne la pente, l'intersection avec les ordonnées, et peut-être même la linéarité des courbes au sein des groupes de marques et même parmi les marques d'un même groupe. En fait, bien que certaines marques semblent être linéaires soit sur des échelles arithmétiques, soit logarithmiques, elles n'en ont pas moins de grandes différences entre elles. Il est également tout à fait évident que le condensat et la nicotine ne sont pas linéaires sur la même échelle, le condensat l'étant approximativement sur une échelle logarithmique et la nicotine l'étant approximátivement sur une échelle arithmétique. Sur la base de ce qui a été dit plus haut, il apparaît clairement que le classement des marques sur la base d'un certain paramètre dépendra fortement de la longueur du mégot pour laquelle le paramètre en question a été mesuré. Pour cette raison, il est évident qu'une comparaison internationale des rendements en fumée exige une redétermination expérimentale de ceux-ci par rapport aux nouvelles longueurs standard de mégot, plutôt que de recourir à des manipulations mathématiques en se basant sur une unique relation fonctionnelle.

On ne peut tirer de cette étude une relation fonctionnelle adéquate pour l'HCN, et des expériences supplémentaires devront être entreprises à cette fin. Les trois autres paramètres, par contre, se prêtaient à l'étude et à l'analyse statistique dans la comparaison de modèles.

\section{REFERENCES}

1. Newsome, J. R., and C. H. Keith: Quantitative studies on cigarette smoke, II. The effect of physical variables on the weight of smoke; Tobacco Sci. 1 (1957) 58-63.

2. Waltz, $P$., and $M$. Häusermann: Betrachtungen über die Veränderung des Tabakrauches in der Cigarette; Beitr. Tabakforsh. 3 (1965) 169-202.

3. Artho, A., and R. Koch: Uber die Bestimmung von Cyanwasserstoff im Cigarettenrauch; Beitr. Tabakforsch. 5 (1969) 58-63.

4. Curran, J. G., and J. E. Kiefer: A method for measuring the elution of nicotine and total particulate matter from a cigarette filter; Beitr. Tabakforsch. 7 (1973) 29-35.

5. Ceschini, P., and D. Cham: Effect of sampling conditions on the composition of the volatile phase of cigarette smoke; Beitr. Tabakforsch. 7 (1974) 294301.

6. Bydkling, E.: Untersuchung der Filterwirksamkeit des Tabakstranges bei Cigaretten verschiedener Härte in Abhängigkeit von der Abrauchlänge; Beitr. Tabakforsch. 8 (1976) 382-391.

7. Fordyce, W. B., X. W. Hughes and M. G. Ivinson: The filtration of cigarette smoke; 'Tob. Sci. 5 (1961) 70-75.

8. Baker, R. R., and R. A. Crellin: The diffusion of carbon monoxide out of cigarettes; Beitr. Tabakforsch. 9 (1977) 131-140. 
9. Muramatsu, M., T. Mikami, N. Naito and H. Tomita: A model study on the diffusion and the dilution of low molecular weight gaseous components through cigarette paper during smoking; Beitr. Tabakforsch. 9 (1977) 141-146.

10. Owen, W. C., and M. L. Reynolds: The diffusion of gases through cigarette paper during smoking; Tob. Sci. 11 (1967) 14-20.

11. Waltz, P., and M. Häusermann: Le rendement en fumée d'une cigarette (Etablissement d'une expression analytique); Coresta Information Bulletin 1963-4, 7-28.

12. Brunnemann, K. D., D. Hoffmann, E. L. Wynder and G. B. Gori: Determination of tar, nicotine and carbon monoxide in cigarette smoke, A comparison of international smoking conditions, XXXVII of Chemical studies on tobacco smoke; Proceedings, 3rd World Conference on Smoking and Health, 1975, Vol. 1, 441-449.

13. Rickert, W. S., J. C. Robinson and J. C. Young: Estimating the hazards of "less hazardous" cigarettes, I. Tar, nicotine, carbon monoxide, acrolein, hydrogen cyanide and total aldehyde deliveries of Canadian cigarettes; Journal of Toxicology and Environmental Health 6 (1980) 351-365.

14. Pillsbury, H. C., C. C. Bright, K. J. O'Connor and F. W. Irish: Tar and nicotine in cigarette smoke; J. Assoc. Off. Anal. Chem. 52 (1969) 458-462.

15. Sloan, C. H., and B. J. Sublett: Moisture content of the particulate phase of smoke from filter and nonfilter cigarettes; Tob. Sci. 9 (1965) 70-76.

16. Rickert, W. S., and P. B. Stockwell: Automated determination of hydrogen cyanide, acrolein and total aldehydes in the gas phase of tobacco smoke; J. Autom. Chem. 1 (1979) 152-154.
17. Snedecor, G. W., and W. G. Cochran: Statistical methods, 6th edition; Univ. of lowa Press, 1971, Ames, lowa.

18. Mumpower, R. C.: Determination of carbon monoxide in cigarette smoke by gas dhromatography; Tob. Sci. 6 (1962) 142-145.

19. Rickards, J. C., and W. F. Owens: Effect of porous cigarette papers on the yield of the major vapor phase and certain particulate phase components of cigarette smoke; 20th Tob. Chemists' Research Conf., Winston-Salem, N.C., 1966.

20. Newsome, J. R., V. Norman and C. H. Keith: Vapor phase analysis of tobacco smoke; Tob. Sci. 9 (1965) 102-110.

\section{Acknowledgements}

Financial support for the analytical portion of this study was provided by a Department of Health and Welfare grant for Research on Drug Abuse while support for the statistical analysis and computing was provided by a grant from the National Science and Engineering Research Council of Canada. We are also grateful for the competent tednical assistance of $\mathrm{J}$. Zaoitsky, V. Patel, K. Schulthies and S. Gibbons.

\section{Addresses of authors:}

Department of Statistics,

University of Waterloo,

Waterloo, Ontario, N2L 3G1, Canada.

Labstat Incorporated, 262 Manitou Drive, Kitchener, Ontario, N2C 1L3, Canada. 